\title{
¿Son indispensables los diccionarios combinatorios?
}

\author{
MERCEDES PÉREZ SERRANO \\ Columbia University
}

\section{NOCIONES PRELIMINARES}

Las afinidades léxicas ya fueron señaladas hace más de un siglo (Bally 1909) pero ha sido en estas últimas décadas cuando el fenómeno colocacional ha atraído la atención de numerosos lingüistas desde muy distintos campos, tales como la sintaxis, la semántica, la lexicología y la fraseología, así como la lexicografía y el procesamiento automático de textos.

Es bien sabido que la noción de colocación no deja de ser problemática, por ser considerada una unidad lingüística a medio camino entre las combinaciones libres y las expresiones idiomáticas. Tal y como se recoge en los textos fundacionales del estudio sistemático de las colocaciones, estas pueden definirse como unidades o frasemas semánticos (Mel'čuk 1998) formadas por dos lexías o constituyentes (Tutin y Grossman 2002). Y son unidades asimétricas porque los dos elementos no gozan del mismo estatus: de acuerdo con la Teoría Sentido-Texto, uno de ellos es la base en la terminología de Haussman (1979) o la palabra llave en la de Mel'čuk (1982) que el hablante selecciona libremente en función de aquello que quiere expresar. Pues bien, esta base o palabra llave selecciona al colocativo o valor(es) respectivamente, es decir, que este se elige en función de la base. En una colocación como fumador empedernido la base fumador selecciona al adjetivo intensificador empedernido, mientras que el sustantivo enemigo selecciona acérrimo para esa misma función de intensificación. De la misma forma, el sustantivo paseo selecciona al verbo dar, mientras que viaje selecciona hacer o bronca selecciona echar en las colocaciones dar un paseo, hacer una viaje o echar una bronca. Autores como Bosque $(2001,2004)$ comparten la noción de la selección como proceso que da lugar a las colocaciones. Sin embargo, para este autor, la dirección opera en sentido contrario, siendo los predicados (dar, echar) los que seleccionan a sus argumentos (paseo, bronca).

Se han señalado los muchos beneficios que reportaría una mayor atención a las colocaciones en el aula de lengua extranjera, entre otros, que el conocimiento colocacional es lo que diferencia a un hablante nativo de uno no nativo en cuanto al uso del vo-

* La idea de este artículo surge de la lectura del de Agnés Tutin «Le dictionnaire de collocations est-il indispensable?» (2005) en el que se compara el acceso a las colocaciones en diccionarios especializados y diccionarios en francés. Este artículo no hubiera sido posible sin la revisión y los comentarios de Marta Higueras y Javier de Santiago Guervós, y la edición de La letra correcta.

MERCEDES PÉREZ SERRANO, «¿Son indispensables los diccionarios combinatorios?», Revista de Lexicografia, XX (2014), pp. 121-145 Fecha de presentación: 08/01/2014 Fecha de aceptación: 10/11/2014 ISSN: 1134-4539, e-ISSN: 2603-667. DOI: https://doi.org/10.17979/rlex.2014.20.0.3877 
cabulario y que contribuyen a una mayor fluidez y precisión (Howarth 1998; Granger 1998; Nesselhauf 2005; Higueras 2006b) y del papel que en ello juegan los diccionarios combinatorios o de colocaciones (Alonso Ramos 2008; Higueras 2005, 2006a).

\section{LAS COLOCACIONES EN LA LEXICOGRAFÍA ESPAÑOLA}

La atención lexicográfica a las colocaciones es un fenómeno relativamente reciente. Se ha indicado en repetidas ocasiones la falta de sistematicidad a la hora de recoger los fenómenos combinatorios y también el hecho de que estos se reflejen de forma insuficiente en los diccionarios (Alonso Ramos y Sanromán Vilas 2000: 97). Sin embargo, como apunta Ruiz Martínez en su estudio sobre el tratamiento de las colocaciones en la parte introductoria de algunos diccionarios monolingües,

$$
\begin{aligned}
& \text { esta situación no impide que las colocaciones estén presentes, si bien de una mane- } \\
& \text { ra no explícita, en la microestructura de muchos diccionarios monolingües del es- } \\
& \text { pañol gracias al empleo de diferentes mecanismos (en la alusión que se hace en la } \\
& \text { definición a las restricciones semánticas combinatorias que tiene una palabra, en } \\
& \text { los ejemplos que completan la información que aparece en la definición, en el em- } \\
& \text { pleo de algunas fórmulas (aplíquese } a \text {, referido a, etc.) para destacar las restriccio- } \\
& \text { nes semánticas del lema, bajo el marbete de locuciones o frases, etc.) (2007: 144). }
\end{aligned}
$$

En cuanto a los diccionarios combinatorios, estos existen para otras lenguas como el inglés, como es el caso del BBI Combinatory Dictionary of English (Benson et al., 1986), el LTP Dictionary of Selected Collocations (Hill and Lewis 1997), el Oxford Collocations Dictionary (Crowther et al. 2002) o el recientemente publicado Macmillan Collocations Dictionary (Rundell 2012); o el francés Dictionnaire explicatif et combinatoire du français contemporain (Mel'čuk et al. 1984, 1988, 1992 y 2000) (DEC en lo sucesivo), el Lexique actif du français (Mel'čuk y Polguère 2007) o el Dictionnaire des coocurrents (Beauchesne 2002). Para el italiano, recientemente se ha publicado Dizionario delle collocazioni (Tiberii 2012).

En el caso del español, actualmente solo se cuenta con una obra lexicográfica específicamente dedicada a las colocaciones: el Diccionario de colocaciones del español (2004) (DiCE, en adelante), dirigido por Margarita Alonso Ramos y que por el momento recoge las colocaciones de los nombres de sentimiento. Por otra parte, existen dos obras lexicográficas dirigidas por Ignacio Bosque que no recogen exclusivamente las colocaciones sino también otros fenómenos combinatorios. Se trata de Redes, publicado en 2004, y el Diccionario combinatorio práctico (DCP, en adelante), en $2006{ }^{1}$.

Es más que reseñable la propuesta que hace Ferrando Aramo (2013) para la compilación de un diccionario combinatorio destinado a la enseñanza-aprendizaje de ELE por niveles. Asumiendo que es posible compilar un diccionario de colocaciones para aunar, en un solo recurso, las colocaciones dispersas en los manuales, la autora propone y demuestra que se puede hacer un diccionario de colocaciones onomasiológico,

${ }^{1}$ Además, existe una obra de Javier Boneu de 2001, el Diccionario euléxico. Para explicarse con estilo y rigor que recoge, según Barrios (2007) una pequeña parte de la combinatoria del español, unas mil ochocientas entradas sustantivas. 
semibilingüe y contrastivo, que marque los niveles de dominio a los que pertenece cada colocación; además, estaría orientado a la producción y disponible en formato electrónico (Ferrando 2013: 9- 10). Su propuesta está dirigida concretamente a aprendientes cuya L1 es el italiano. Confiamos en que se siga trabajando en esta línea para llegar a la compilación de un diccionario combinatorio dirigido a hablantes no nativos de español y que sea accesible a los aprendientes, sin importar su nivel de dominio.

\section{1. $E l \mathrm{DiCE}$}

El DiCE es un diccionario de colocaciones en formato electrónico y disponible en línea que cubre las colocaciones y las derivaciones semánticas de los nombres de sentimiento. Se trata de una base de datos electrónica concebida como tal desde el primer momento, lo que, como apunta su directora, lo libera del orden alfabético de otros diccionarios (Alonso Ramos 2010: 11).

Sigue la orientación de la lexicología explicativa y combinatoria (LEC, en lo sucesivo) de Mel'čuk y su equipo de la Universidad de Montreal, que cuentan con la publicación del DEC en cuatro volúmenes $(1984,1988,1992$ y 2000) y su versión dirigida a un público más general, Lexique actif du français (2007).

Las obras que siguen este modelo se estructuran en dos ejes de descripción, que corresponden, respectivamente, a los ejes paradigmático y sintagmático: las derivaciones semánticas - una relación entre dos lexías basada en un parentesco de sentido, lo que engloba a (cuasi)sinónimos y (cuasi)antónimos - y las colocaciones.

El instrumento teórico que se utiliza para la modelización de ambos ejes es el de función léxica. Se trata de una relación de dependencia o una correspondencia $f$ que asocia a una unidad léxica $L$ (llamada el argumento o la palabra llave de f) un conjunto de unidades léxicas $\mathrm{f}(\mathrm{L})$ que expresan un sentido específico asociado a dicha función y al que se le llama el valor de la función.

Las funciones léxicas paradigmáticas —o derivaciones semánticas- hacen referencia al principio de selección y aluden a un conjunto de correlatos léxicos relacionados con una unidad léxica. Utilizando el ejemplo del autor Mel'čuk (1998), la unidad léxica school, tendría asociadas las unidades léxicas students, subject, exam, lesson, mark, class, [to] teach, etc.

Por su parte, las funciones léxicas sintagmáticas hacen referencia al principio de combinación y aluden a un conjunto de correlatos léxicos de una unidad léxica y que forman con ella colocaciones. Son las funciones que ofrecen un mayor interés para este trabajo, porque suponen el aparato teórico que el modelo sentido-texto, bajo el que se encuadran los diccionarios de Mel'čuk, utiliza para explicar el fenómeno colocacional. Por seguir con el ejemplo de school sus correlatos léxicos sintagmáticos serían high/ elementary (school); go (to school); graduate (from school).

Así, pues, cada lema del DiCE se compone de una o varias unidades léxicas, para cada una de las cuales se presenta, en cuanto a la información semántica, una etiqueta semántica, la estructura actancial, ejemplos de corpus y cuasisinónimos y cuasiantónimos. En cuanto a la información combinatoria, se muestra el esquema de régimen de la unidad léxica y sus colocaciones. 
La LEC propone la elaboración de diccionarios desde la perspectiva de la producción o la codificación. Es decir, que son diccionarios concebidos para ayudar a expresarse, a codificar el pensamiento, y por ello contrastan con otros diccionarios al uso concebidos para ayudar a comprender el significado de los enunciados. Como declaran Mel'čuk y Polguère (2007) en la introducción al Lexique actif du Français, están diseñados no a responder preguntas del tipo «¿qué significa esta palabra o expresión?» sino más bien del tipo «¿cómo se expresa este significado?».

Más concretamente, como declara Alonso Ramos, el objetivo principal de un diccionario de colocaciones es «proporcionar las unidades léxicas que son seleccionadas de un modo restringido por otra unidad léxica previamente elegida» (2008: 2). Así, por ejemplo, registra qué verbos significan 'empezar a sentir' cuando se habla de cariño o de afecto, cobrar y coger.

\subsection{Redes y el DCP}

Antes de nada conviene aclarar que estos dos diccionarios combinatorios no se ciñen exclusivamente a las colocaciones sino que son diccionarios de restricciones combinatorias, fenómeno en el que quedan incluidas las colocaciones. Bosque entiende la relación entre «el colocativo y sus bases como un caso particular de la relación entre un predicado y sus argumentos, lo que convierte a las colocaciones en casos específicos de selección léxica» (2001: 15).

\subsubsection{Redes}

A diferencia del DiCE y de los otros diccionarios de la LEC, en Redes (2004) se lematiza el colocativo en la terminología anterior. Así, para la colocación desear ardientemente, esta vez el lema sería el adverbio. En su entrada se informa de que que ardientemente se predica de un verbo como desear. Y su objetivo principal es «mostrar qué uso figurado hace el idioma de la palabra ardientemente» (2001: 33).

Como se ha dicho en varias ocasiones (Alonso Ramos 2002; Barrios, 2007), los enfoques lexicográficos defendidos por Alonso Ramos - el de la teoría sentido-texto (TST, en adelante), que entiende la dirección de las relaciones léxicas de los argumentos a los predicados - y por Bosque (2004) — que las entiende de los predicados a los argumentos - son complementarios. Pues bien, desde el punto de vista del que aprende español como segunda lengua, no solo creemos que ambos enfoques son complementarios sino también necesarios. Si bien los diccionarios de la LEC (con su lematización de las bases) pueden resolver dudas comunicativas concretas («¿Qué adverbio se utiliza para intensificar la acción de amar?» «Intensamente»); los diccionarios dirigidos por Bosque nos ayudan a profundizar en el conocimiento cualitativo de una palabra ${ }^{2}$ («¿Cómo se usa el adverbio intensamente?» «De qué verbos se predica?»).

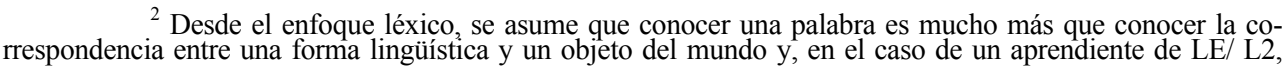
mucho más que conocer la equivalencia con su L1. Nation (2001) propuso un esquema en el que resume todos aquellos aspectos implicados en el conocimiento de una palabra. Entre ellos están los aspectos que configuran
} 
Redes coincide con los diccionarios derivados de la TST en intentar dotar de contenido a las combinaciones léxicas que en otros proyectos solo se presentan como combinaciones frecuentes (como en el $B B I$ ). Pero, como anuncia su director en la introducción al diccionario, Redes pone el énfasis en otros aspectos de la descripción: las entradas abreviadas de Redes no son abreviadas en el DiCE, sino el centro del análisis combinatorio que se presenta en esas obras. El fundamento de Redes es el concepto de selección léxica: los predicados restringen a sus argumentos, es decir, acotan el conjunto de nociones que estos pueden designar y lo reducen de manera muy diversa.

Redes tiene dos tipos de entradas, analíticas y abreviadas, que se diferencian no solo en extensión sino también en estructura. Todos los lemas de las entradas analíticas son predicados. Por ello, la direccionalidad es opuesta a la de los diccionarios del marco de la LEC, porque en Redes se describe la forma en que los predicados seleccionan a sus argumentos. De esta forma, si el lema es un adjetivo (acérrimo), en la entrada aparecerán los sustantivos de los que este se predica (fan, enemigo, rival); si es un verbo (albergar), también aparecerán argumentos nominales en su entrada (esperanza, deseo, expectativa) y en la de un adverbio (religiosamente) aparecen verbos (pagar, ingresar, acudir). Las entradas abreviadas contienen referencias cruzadas a los predicados y a las clases léxicas. Por ejemplo, si buscamos deseo encontraremos que los deseos se abrigan, se albergan, se alimentan, brotan, son ciegos, abrasadores, acuciantes, etc. Para resumir: los tres elementos en juego — predicados, argumentos y relación significativa que se establece entre ellos - están lematizados en Redes, si bien se profundiza en los argumentos, lemas de las entradas analíticas.

\subsubsection{El DCP}

Es un diccionario de 14.000 entradas que surge como desarrollo de su antecesor Redes. Como ya avanza su director en la introducción, la diferencia principal con Redes es que en el DCP «se pone mayor énfasis en el uso del idioma que en el análisis de sus estructuras» (2006: XIII). En este sentido, se salvan los escollos que Redes puede presentar a un aprendiente no iniciado en lingüística.

El DCP contiene entradas de tres tipos, las simples, en las que se describen las combinaciones de una palabra determinada; las genéricas, en las que se describen combinaciones que se aplican a una determinada noción semántica como ropa, instrumento musical; y las remisiones, en las que se envía a otras entradas.

No se trata de un diccionario de colocaciones porque, como reza la introducción, los autores no estaban dispuestos a asumir ese «riesgo conceptual» (2006: XVII), pues en muchos otros diccionarios bautizados como diccionarios de colocaciones se dan cabida a otras asociaciones semánticas, sintácticas o léxicas de otro tipo.

En cuanto a qué parte de la colocación se lematiza, según Bosque, en el DCP se opta por una solución más equilibrada que en Redes y las dos direcciones reciben el mis-

el conocimiento de una palabra que forman parte de la competencia léxica y que responden a preguntas como ¿qué palabras aparecen con ella?, relacionados con el conocimiento receptivo, y ¿qué otras palabras puedo usar junto a ella?, como conocimiento productivo. 
mo tratamiento. Por tanto, reciben igual tratamiento los nombres, verbos, adverbios y adjetivos, porque, «el usuario debe conocer la relación que existe entre su significado y su empleo, y también porque en muchos casos admiten usos físicos y figurados, que es imprescindible conocer y manejar con cierta soltura» (2006: XVIII-XIX).

De esta manera, un hablante que quiera saber qué unidad léxica expresa el sentido de 'empezar a sentir' cuando habla de manía lo encontrará en la entrada de manía. Como en otros diccionarios de colocaciones, la base constituye un lema que el usuario puede buscar a la hora de producir enunciados. Los sentidos de los distintos verbos seleccionados se separan por una doble barra:

manía s.f.

CON ADJS. extravagante $\cdot$ estrambótica $\cdot$ excéntrica $\cdot$ peculiar $\cdot$ insólita extraña Tiene la extraña manía de ... $\cdot$ rara $\cdot$ curiosa $\|$ asentada $\cdot$ extendida arraigada $\cdot$ obstinada $\cdot$ continua $\cdot$ pertinaz $\cdot$ incorregible $\|$ enfermiza $\cdot$ obsesiva $\cdot$ persistente || persecutoria $\cdot$ peligrosa $\cdot$ funesta $\|$ inofensiva $\cdot$ inocente $\|$ vieja $\cdot$ antigua $\cdot$ nueva

CON VBOS. entrar (a alguien) Últimamente le han entrado un montón de manías · dar (a alguien) · venir (a alguien) $\|$ quitarse(le) (a alguien) · írse(le) (a alguien) $\|$ extenderse $\|$ abolir $\cdot$ erradicar $\cdot$ desterrar $\cdot$ corregir Tienes que corregir esa manía que te ha dado ahora de morderte las uñas · superar · vencer · combatir || adquirir $\cdot$ coger $\cdot$ tener $\cdot$ presentar $\cdot$ sufrir $\|$ contar (con)

Pero, a diferencia de otros diccionarios combinatorios como los de la LEC, también constituye un lema el colocativo, en este caso el verbo coger. Lo que defiende Bosque es que estas entradas, que son «las que nadie busca» (2006: xviii) (y que constituían las entradas principales en Redes), tienen una gran densidad conceptual. Su lematización permite que el usuario que quiera conocer el empleo del verbo coger en español, lo encontrará en la entrada de este verbo:

coger $\mathrm{v}$.

CON SUSTS. vuelo $\cdot$ autobús $\cdot$ tren $\cdot$ avión $\cdot$ taxi $\cdot$ barco $\cdot$ metro $\cdot$ coche $\cdot$ otros medios de transporte || teléfono ¿Coges tú el teléfono que yo no puedo? || cariño coger cariño a una persona $\cdot$ gusto $\|$ miedo $\cdot \operatorname{manía} \cdot$ odio $\cdot$ aversión $\|$ infección · sida $\cdot$ sarampión $\cdot$ virus $\cdot$ depresión $\cdot$ otras enfermedades $\|$ borrachera \| vacaciones · día · permiso El sesenta por ciento de los ciudadanos coge el permiso estival en el mes de...

CON ADVS. con las manos en la masa - in fraganti Cogieron al ladrón in fraganti $\|$ a contramano $\cdot$ a contrapelo $\cdot$ a trasmano $\|$ firmemente $\cdot$ con firme$\mathbf{z a} \cdot$ con mano firme $\cdot$ en falso $\|$ a pulso $\cdot$ al vuelo Cogí la indirecta al vuelo $\cdot$ en volandas Cogió al herido en volandas y lo metió en el coche $\|$ por los pelos · de milagro || gravemente

Ambas entradas pueden ofrecer interés al usuario. La de manía resolvería una necesidad comunicativa concreta que puede surgir en la producción lingüística. La de coger profundizaría en el conocimiento cualitativo de este verbo y ayudaría a establecer relaciones entre las palabras que aparecen con coger en el sentido de 'empezar a sentir': cariño, gusto, miedo, manía, odio, aversión. 


\section{EL ACCESO A LAS COLOCACIONES EN LOS DICCIONARIOS}

\subsection{El Diccionario de la Real Academia Española (DRAE-2001)}

La edición que está disponible en línea es la vigesimosegunda, de 2001. En esta edición observamos cambios significativos respecto de las anteriores en cuanto al tratamiento de las colocaciones.

La Academia utiliza por primera vez en esta edición vez el término formas complejas en el apartado 3.3. Colocación de las formas complejas dentro del Diccionario, donde se explican acudiendo al criterio de composicionalidad:

además de registrar las entradas constituidas por una sola palabra (p. ej., perla, aceite, susto), el Diccionario recoge series de palabras que, combinadas de una determinada manera, expresan conceptos no interpretables mediante la simple adición de los significados de sus componentes (de perlas, aceite virgen, no ganar para sustos).

De acuerdo con la terminología que estamos empleando aquí, en el DRAE se lematizan en principio las bases sustantivas, de tal forma que aceite virgen se encontrará en la entrada de aceite y agua de colonia en agua.

Es importante señalar que la Academia utiliza el término formas complejas y en él engloba tanto los compuestos sintagmáticos agua de colonia como las locuciones del tipo mano de santo.

Sin embargo, tal y como apunta Ruiz Martínez (2007: 149), «aunque la Academia incorpore bajo el mismo marbete el concepto de colocación y el de unidad fraseológica, sí establece una determinada organización a la hora de incluir todo este material en el diccionario». Así, por ejemplo, si acudimos al apartado 5.4 Formas complejas, se nos explica la organización de las mismas: «en el primer bloque aparecen las combinaciones estables del lema con otros elementos que desempeñan una función adjetiva con respecto a él. En el segundo, las locuciones, expresiones, frases e interjecciones». Así pues, el término colocación no aparece de forma explícita pero se engloba dentro de la denominación combinaciones estables, si bien solamente se cubren aquí las formadas por un sustantivo y un adjetivo.

Tras una búsqueda minuciosa de distintas unidades léxicas y de observar el acceso a su combinatoria, hemos observado que se dan los siguientes casos:

a) Entradas en las que podemos encontrar la otra parte de la colocación en la misma definición:

contraer. [...] 4. tr. Adquirir costumbres, vicios, enfermedades, resabios, deudas, etc. 5. tr. Asumir obligaciones o compromisos.

b) Entradas en las que encontramos la otra parte de la colocación introducida por se dice de o dicho de:

aguileño, ña.1. adj. Dicho del rostro: Largo y delgado. 2. adj. Dicho de una persona: Que tiene el rostro aguileño.

c) Entradas que figuran en la sección denominada formas complejas, en cuyo caso se explica el significado de la colocación de forma explícita. 
vergüenza. ajena. f. La que uno siente por lo que hacen o dicen otros.

café. $\sim$ puro, o $\sim$ solo. m. café sin leche.

paseo dar un $\sim$.1. loc. verb. Pasear a pie. 2. loc. verb. Pasear a caballo, o en un carruaje o embarcación.

d) Casos en los que las colocaciones figuran en los ejemplos que se aportan después de alguna acepción en color morado.

garrafal. [...] 3. adj. Se dice de algunas faltas graves de la expresión y de algunas acciones. Error, mentira garrafal.

contraer. $[\ldots]$ 2. tr. Celebrar el contrato matrimonial. Contraer matrimonio. Contraer nupcias.

perder. [...] 10. tr. Faltar a una obligación o hacer algo en contrario. Perder el respeto, la cortesía.

e) Casos de remisiones: en algunos casos, se remite a una forma compleja que aparece en la entrada del otro integrante de la dicha forma compleja. Así, por ejemplo, hemos visto que en la entrada de vino aparece vino tinto en la sección de formas complejas. Pues bien, si buscamos tinto, nos remite a la entrada de vino, a la sección de formas complejas.

Estas remisiones pueden ocurrir bien dentro de una acepción:

tinto, ta. [...] 3. m. vino tinto.

O bien dentro de un apartado encabezado por véase (V.), dedicado exclusivamente a remisiones.

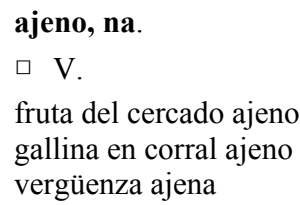

Las conclusiones que podemos extraer de este primer acercamiento son las siguientes:

$1^{\circ} \quad$ El DRAE no es sistemático en cuanto al tratamiento de la información en la entrada de la base o del colocativo. Se registran casos en los que la base aparece en la entrada del colocativo, pero no viceversa (en la entrada de garrafal aparece error pero en la entrada de error no aparece garrafal); casos en los que el colocativo aparece en la entrada de la base (en la entrada de paseo aparece como locución dar un paseo); y también hemos encontrado casos donde se puede llegar a la colocación desde ambas direcciones, como es el caso de vergüenza ajena, que aparece registrada tanto en la entrada de vergüenza, como en la de ajena.

$2^{\circ} \quad$ La adscripción de estas unidades lingüísticas — si bien sabemos que no está exenta de polémica - a una u otra categoría varía. Como ya hemos repasado, algunas aparecen sin marcar dentro de la definición o los ejemplos, otras se engloban dentro de lo que el DRAE llama formas complejas y dentro de estas, algunas aparecen marcadas como locuciones verbales. 
$3^{\circ}$ Dentro de este apartado de formas complejas se incluyen tanto colocaciones como frases idiomáticas ${ }^{3}$, de tal forma que encontramos la colocación apagar el hambre aparece bajo esta rúbrica igual que juntarse el hambre con las ganas de comer.

$4^{\circ} \quad$ No se registran las colocaciones cuyo colocativo es un adverbio o una locución adverbial, es decir las de verbo + adverbio/ locución adverbial o adverbio/ locución adverbial + adjetivo como plenamente satisfecho, dormir profundamente, pillar con las manos en la masa, locamente enamorado, amenazar peligrosamente, esforzarse vanamente, desear fervientemente, fracasar estrepitosamente ${ }^{4}$.

\title{
3.2. Diccionario Clave: Diccionario de uso del español actual (SM, 2002)
}

El término colocación tampoco aparece registrado en la introducción de Clave, si bien se hace alusión al contorno de las definiciones:

\begin{abstract}
El contorno de la definición ofrece información valiosa que se refiere, por ejemplo, al tipo de sustantivos a los que puede acompañar un adjetivo o a los complementos que pueden aparecer con un determinado verbo. En el caso de los adjetivos, en ese contorno se explicita el tipo de sustantivo al que dicho adjetivo puede acompañar (ejemplo: salvaje no significa lo mismo referido a un animal, a una planta o a un terreno). En el caso de los verbos, la fórmula permite extraer el sujeto, el complemento directo o el complemento preposicional regido (ejemplo: existen diferencias apreciables entre alimentar a un ser vivo, alimentar el fuego o alimentar un sentimiento).
\end{abstract}

Las locuciones, sin embargo, sí aparecen marcadas como tales y se incluyen en el artículo de su primera palabra fuerte, según el siguiente orden de prioridad: sustantivo, verbo, adjetivo, pronombre, adverbio. Así, por ejemplo, la locución no dar un palo al agua aparece definida en palo y no en dar. Sin embargo, esta es una información de la que no dispone un no nativo, por lo que nunca va a llegar a esta locución cuando se le presenta una necesidad léxica a la hora de la producción lingüística. En todo caso, la podrá descodificar si la lee en un texto.

Fijémonos en el tratamiento de las colocaciones en la entrada de algunas bases. Por ejemplo, si buscamos la unidad léxica vergüenza podemos ver que se registran tres colocaciones. Dos de ellas se extraen de los ejemplos y por tanto, su significado no se explica (rojo de vergüenza 'que manifiesta corporalmente' y tener vergüenza, 'sentir vergüenza'). La tercera se incluye dentro de la información del contorno: vergüenza ajena. En este caso sí que se glosa el significado:

\footnotetext{
${ }^{3}$ La literatura especializada suele distinguir entre frases idiomáticas y colocaciones. El criterio principal para diferenciarlas es la composicionalidad. El significado de una frase idiomática compuesta por A y $\mathrm{B}$ es $\mathrm{C}$ y C no incluye ni el significado de A ni de B. El significado de las colocaciones incluye intacto el significado de uno de sus constituyentes, A o B, pero el del otro está condicionado por el primero (Mel'čuk 1998).

${ }^{4}$ Sí aparece, sin embargo, fracaso estrepitoso dentro de la entrada de estrepitoso.
} 
vergüenza ver·güen $\cdot z a$

s.f.

1 Sentimiento de turbación producido por alguna falta cometida o por alguna acción que se considera deshonrosa, humillante o ridícula: Me puse rojo de vergüenza cuando el profesor me pilló copiando en el examen.

2 Sentimiento de dignidad personal o estimación de la propia honra: Si es que tiene vergüenza, reconocerá su error.

3 Acción que atenta contra la dignidad o contra la honradez y deja en mala opinión al que la ejecuta: Es una vergüenza que los niños mueran de hambre.

4 Deshonor o deshonra: Eres la vergüenza de la familia.

p.

5 col. En una persona, órganos sexuales externos: Los nativos de la película cubrían sus vergüenzas con un taparrabos.

- vergüenza ajena s.f.

La que se siente por faltas o acciones cometidas por otros: Si vas vestido como un mamarracho, yo no voy contigo, porque me da vergüenza ajena.

ETIMOLOGíA Del latín verecundia (reserva, pudor, respeto).

Si decidimos buscar por los colocativos, comprobamos que no hay referencia a la unidad léxica vergüenza en ninguna de las tres entradas: ajeno/a, rojo/a o tener. No obstante, en este último caso sí se hace alusión al hecho de que cuando la unidad léxica selecciona sustantivos que forman clases léxicas de sensación, significa 'sentirla, vivirla o padecerla' y pone el ejemplo de «tengo miedo a los monstruos».

Centrémonos ahora en el término duda. Aparecen de forma implícita en los ejemplos las colocaciones poner en duda y no caber $d u d a$, la primera en un ejemplo y la segunda en una nota de sintaxis:

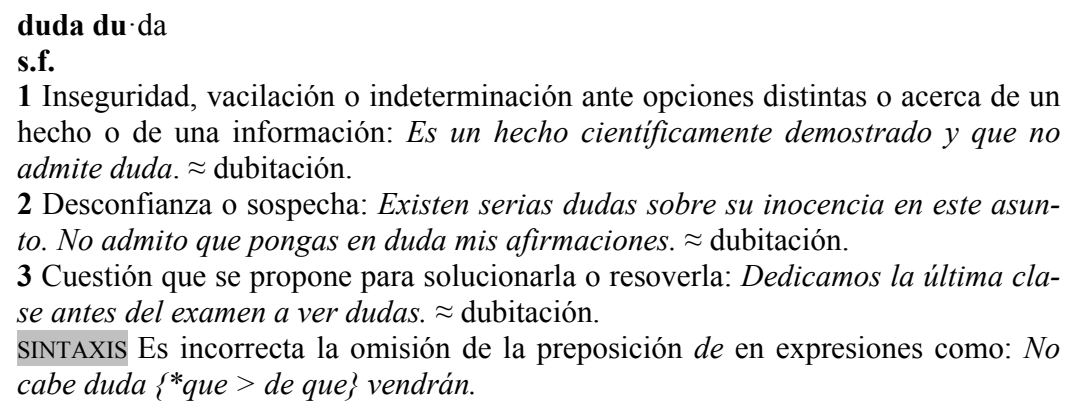

En el caso de las entradas de los colocativos de duda, encontramos no caber duda en la entrada de caber, en un ejemplo, mientras que en la de poner no se registra la colocación poner en duda. Si buscamos otros colocativos frecuentes como albergar, encontramos la acepción de 'guardarlos en la mente o en el corazón' referido a una idea o a un sentimiento.

Hemos podido constatar que las colocaciones en Clave aparecen en las siguientes ubicaciones:

a) En la propia definición de la unidad léxica:

meta me ta

4 Fin u objetivo que se pretende alcanzar. 
b) En las definiciones, introducidas por referido $a$. Es frecuente que esto ocurra en los lemas de verbos que constituyen la base de colocaciones muy restringidas.

contraer con tra $\cdot$ er

2 Referido esp. a una enfermedad o a un vicio, adquirirlos o caer en ellos: Contrajo el sarampión con cuatro meses.

promulgar pro $\cdot \mathrm{mul} \cdot \mathrm{gar}$

1 Referido a una ley o a una disposición de la autoridad, publicarlas formalmente para que sean cumplidas obligatoriamente: El Gobierno promulgará nuevas leyes sobre la utilización del material informático.

proclamar pro cla $\cdot$ mar

2 Referido esp. a un reinado o a una forma de gobierno, declarar solemnemente su comienzo: Tras el fracaso de la monarquía de Amadeo I, fue proclamada la Primera República española.

c) En la información del contorno que aparece después de las distintas acepciones. En este caso, aparece explicado el significado de las colocaciones:

fumador, $-\mathbf{a}$ fu·ma $\cdot$ dor, do $\cdot$ ra

- fumador pasivo s.m.

El que no fuma, pero respira habitualmente el humo de personas fumadoras que están a su alrededor: Soy fumadora pasiva, porque en mi oficina todo el mundo fuma continuamente menos yo.

Hemos observado que en esta información de contorno aparecen incluidas tanto colocaciones como expresiones idiomáticas. Es decir, para la entrada café, por ejemplo, aparece en este apartado una colocación como café americano y una expresión idiomática como mal café.

café ca·fé

- mal café s.m. col.

1 Mal humor: Está de mal café porque le han puesto una multa.

- café americano s.m.

El preparado con mucha agua.

d) Como información implícita que se puede extraer de los ejemplos:

paseo $\mathrm{pa} \cdot \mathrm{se} \cdot \mathrm{o}$

1 Desplazamiento por distracción o por ejercicio, esp. si se hace a pie: Dimos un paseo por la playa. Nos fuimos a dar un paseo a caballo.

empedernido, da em·pe $\cdot$ der $\cdot \mathbf{n i} \cdot \mathrm{do}$, da

Referido a una persona, que es muy persistente o incorregible en el mantenimiento de una actitud, de una costumbre o de un vicio, por tenerlos muy arraigados: una fumadora empedernida.

e) Como definición cuyo significado equivale al significado del lema. Esto ocurre fundamentalmente en las construcciones con verbo de apoyo:

duchar du.char

1 Dar una ducha: El padre advirtió al niño: "jTe duchas tú o te ducho yo!». Se levantó y se duchó con agua fría para espabilarse. 
Del análisis y reflexión sobre la información colocacional que nos ofrece Clave, deducimos las siguientes conclusiones:

$1^{\circ} \quad$ No es sistemático a la hora de ubicar las colocaciones dentro de la entrada: la mayoría de las colocaciones se encuentran como información implícita en los ejemplos y en otros casos en la información de contorno. No debemos olvidar, sin embargo, que la primera edición de Clave es de hace casi veinte años, un momento en el que las colocaciones no estaban tan presentes ni en la práctica lexicográfica española ni en la didáctica de ELE.

$2^{\circ} \quad$ La información de contorno mezcla colocaciones con expresiones idiomáticas: por ejemplo, en la entrada de café, aparecen tanto café americano como mal café (con el significado de 'mal humor').

$3^{\circ}$ Muchas colocaciones, las que aparecen en los ejemplos, no quedan explicadas.

$4^{\circ} \quad$ Aparece implícito el concepto de clase léxica que se desarrolla en Redes. Se han registrado varios lemas verbales que se entenderían como predicados que seleccionan sus argumentos, introducidos por referido a o seguido de. Se aprecia, sin embargo, la imprecisión a la hora de nombrar estas clases léxicas: como es el caso de TOMAR, cuya duodécima acepción dice «Seguido de algunos sustantivos: realizar la acción expresada por estos: Hace poco que lo conozco, pero ya le he tomado cariño». En otros casos, añade sinónimos del verbo cuando va acompañado de una determinada clase de sustantivos, como es el caso de coger que, en la decimotercera acepción, referido a una enfermedad o estado de ánimo, significa 'contraerlo', y los sinónimos son atrapar, agarrar, pillar, pescar.

\subsection{Comparación de la información colocacional diccionarios generales y especializados}

Ya hemos visto la disposición de la información sobre las colocaciones de las palabras en los cuatro diccionarios que son objeto de estudio. Trataremos ahora de ofrecer información cuantitativa acerca del número de colocaciones que estos ofrecen.

Para ello, nos centraremos en cinco nombres de sentimiento ${ }^{5}$ y cuantificaremos los colocativos verbales que aparecen en los cuatro diccionarios. Los nombres son vergüenza, culpa, coraje, deseo y admiración.

En primer lugar, podemos observar que no todos los sustantivos tienen el mismo número de colocativos.

Como era de esperar, el número de verbos que aparecen para expresar distintas nociones junto a estos nombres de sentimiento es mucho más elevado en los diccionarios especializados. Entre ellos, el DiCE registra un mayor número de colocaciones que el DCP en la mayoría de los casos. Entre los diccionarios generales, se han registrado más en Clave pero la diferencia es muy poco significativa.

\footnotetext{
${ }^{5}$ Hemos decidido analizar los colocativos verbales de nombres de sentimiento porque queríamos incluir en el análisis el DiCE.
} 


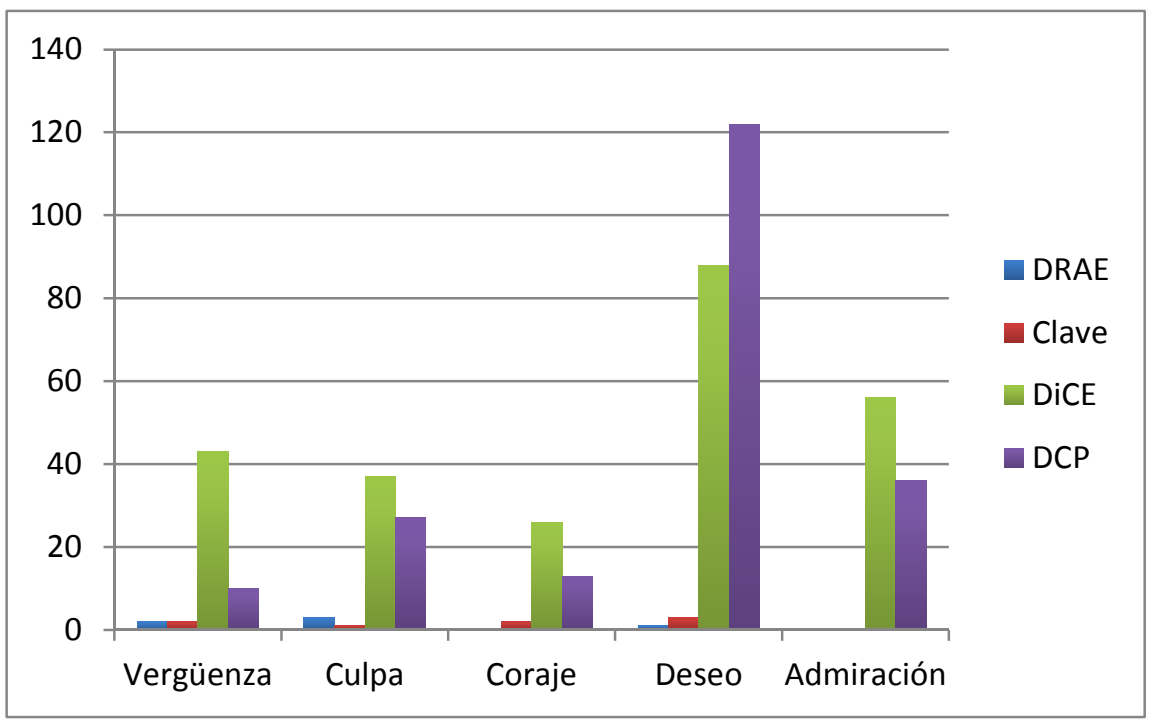

Figura 1: Aparición de verbos junto a algunos nombres de sentimiento

\section{INFORMACIÓN SINTÁCTICA Y SEMÁNTICA DE LAS COLOCACIONES:}

A lo largo de este artículo nos hemos ceñido a las colocaciones léxicas y su acceso en el diccionario. No obstante, es bien sabido que a la hora de la codificación, los aprendientes de español también se plantean otra serie de cuestiones de carácter paradigmático, a saber: el régimen preposicional — lo que Lewis llama la gramática de las palabras - o la posibilidad de aparición de determinantes o modificadores. Para valorar la aparición de la información sintáctica que aparece en los diccionarios objeto de estudio, al igual que hace Tutin (2005) en su comparación de los diccionarios para el francés, nos fijaremos en tres aspectos de colocaciones verbo-nombre:

- $\quad$ El régimen preposicional de algunas colocaciones.

- La aparición de determinantes o m odificadores del nombre ${ }^{6}$.

- La pluralización del nombre de la colocación.

Asimismo, desde esta perspectiva didáctica, puede resultar útil al aprendiente una glosa o explicación del significado de la colocación con ejemplos que muestren su

${ }^{6}$ Sanromán (2009: 247-248) diferencia entre los nombres de causa interna, como respeto, odio, cariño o simpatía, «que nacen en el propio experimentador como consecuencia de una valoración que este hace acerca de una entidad del mundo» y los nombres de causa externa como asombro, enfado, satisfacción o ira, «para los que es necesaria la existencia de un hecho externo al experimentador que desencadene tal reacción emocional». La autora estudia su comportamiento colocacional y concluye que los primeros se combinan libremente con tener con el significado de 'sentir': tener aversión, tener simpatía, tener apego... Los segundos, cuando se combinan con tener frecuentemente llevan un artículo intensivo: tengo una ilusión enorme por cantar una ópera. 
empleo porque, si bien es cierto que muchas colocaciones no son difíciles de decodificar, las cosas se tornan algo más complicadas a la hora de producirlas.

\subsection{La información sintáctica y semántica en el DRAE y en Clave}

Podemos decir que, en términos generales, la información que aparece en estos dos diccionarios acerca de la configuración sintáctica de las colocaciones y la información semántica que expresan es insuficiente desde la perspectiva de un aprendiente de ELE que quiere producir un texto.

Para empezar, el régimen preposicional de los nombres de sentimiento no aparece tratado de forma suficiente. Por ejemplo, en el caso del DRAE no aparece la preposición de para introducir la causa o el origen de miedo, ni las preposiciones $a$ o por para introducir el objeto de apego. Si el nombre, con su preposición correspondiente, forma parte de lo que se consideran las ya mencionadas formas complejas, entonces puede aparecer en rojo y puede deducirse el régimen preposicional, como es el caso de temor, entrada en la que se registra temor de Dios. No obstante, se han encontrado otros casos donde la información es más explícita: en la entrada de aversión, si bien no aparece el colocativo verbal, sí aparece su régimen preposicional. Registra las preposiciones que introducen al objeto de este sentimiento, destacándolas en mayúsculas y marcándolas con otro color:

aversión. (Del lat. aversĭo, -ōnis). f. Rechazo o repugnancia frente a alguien o algo. Aversión A los espacios cerrados, HACIA las serpientes, POR la impuntualidad.

En el caso de Clave, hemos encontrado que en muchas entradas el esquema de régimen se deduce de los ejemplos. Es el caso de miedo, aversión, esperanza, temor. Así, para el nombre aversión, aparecen dos de las preposiciones que introducen el objeto de la aversión, a y por:

\section{aversión a·ver·sión}

s.f.

Antipatía o repugnancia exageradas hacia algo: Tiene verdadera aversión al pescado. Siento aversión por los insectos.

Como en el caso de aversión, hemos encontrado varios donde el régimen preposicional aparece también en el ejemplo:

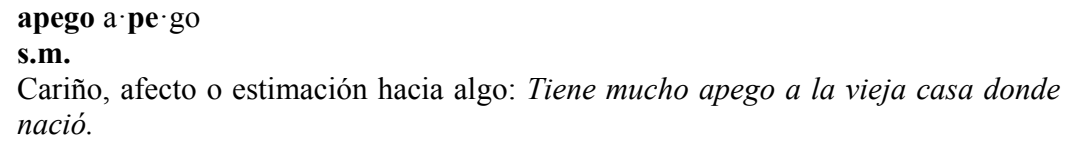

Hay casos en los que se incluye otro tipo de información sintáctica, como por ejemplo la posibilidad de pluralizar algunos nombres aparece en algunos casos, como en gana, donde sí se hace mención explícita a la utilización de ambas formas, gana y ganas:

gana.f. Deseo, apetito, voluntad de algo. U. t. en pl. con el mismo significado que en sing. Ganas DE comer, DE dormir

Sin embargo, en otros casos se obvia esta información. En la entrada de la unidad léxica celo, aparece la combinación dar celos — donde, por cierto, sí aparece la estruc- 
tura actancial-, si bien se omite una explicación del porqué del plural en este caso, o la diferencia respecto a la utilización del singular:

$\mathbf{d a r} \sim \mathbf{s}$ alguien a otra persona. 1. loc. verb. Darle motivo para que los sienta.

En el caso de Clave, se dedica una acepción entera al significado habitual de celos, aunque se puntualiza que es el nombre en plural el que significa:

5 Sospecha, inquietud o temor de que la persona amada prefiera a otro antes que a uno mismo: Los celos infundados del esposo acabaron por arruinar su matrimonio.

Si bien esta información es más explícita que en el DRAE, también es cierto que no aparecen sus colocativos verbales más comunes, ni siquiera en el ejemplo: dar celos, sentir celos, tener celos.

En cuanto a gana, hemos comprobado en el Corpus del español (Davies: 2002) que con el colocativo tener aparecen 238 registros de tener ganas frente a solo dos de tener gana ${ }^{7}$. Podría decirse, pues, que la colocación es tener ganas, que aparece en el ejemplo de la primera acepción:

gana ga $\cdot$ na

1 Deseo, apetito o voluntad de algo: Tengo muchas ganas de ir al cine. No mostró ninguna gana de volver a verlo.

Asimismo, la información sobre la presencia o ausencia del artículo, cuando aparece lo hace de forma implícita y se ha de deducir de los ejemplos. Por ejemplo, el nombre satisfacción se combina con tener para expresar 'sentir'. Si buscamos en el CREA, no existen casos para ninguna de las formas del presente tener en combinación con satisfacción sin determinante. Sí existen casos para las formas tengo la satisfacción, tiene la satisfacción, etc. En el DRAE, por su parte, esta información solo aparece de forma implícita y resulta verdaderamente difícil de obtener para un estudiante de español, especialmente a partir de un ejemplo:

satisfacción. [...] 3. f. Presunción, vanagloria. Tener mucha satisfacción de sí mismo.

En Clave, esta información también se deduce de los ejemplos en algunos casos, como en el de satisfacción:

satisfacción sa·tis·fac·ción

1 Gusto o placer que se siente por algo: Tengo la satisfacción de presentarte a este chico.

\subsection{La información sintáctica y semántica en el DCP}

En general, en el DCP se opta por no especificar las funciones sintácticas en las entradas para facilitar la consulta a los usuarios que no tengan formación gramatical.

Las entradas del DCP se estructuran en torno a criterios sintácticos, que sus autores denominan grupos combinatorios, que son grupos de palabras que se combinan con el lema en función de la clase gramatical a la que pertenecen. De esta forma, un lema se

\footnotetext{
${ }^{7}$ Búsqueda realizada en documentos del siglo Xx y apariciones en periódicos y en español oral.
} 
combina con palabras agrupadas en diferentes clases gramaticales: un sustantivo como miedo se combina con adjetivos (atroz, espantoso, aterrador, etc.), con sustantivos (ataque de, ola de) y con verbos (acechar, planear, acuciar, etc.). Ante una entrada como esta, la pregunta es ¿qué posición sintáctica ocupa miedo cuando se combina con tales verbos? ¿Sujeto? ¿Objeto? ¿Complemento de régimen? Tal y como se afirma en la introducción (2006: LII), los grupos combinatorios verbales que aparecen en las entradas de lema nominal están ordenados sintácticamente. Observemos la ya mencionada entrada de miedo: en primer lugar, se muestran los verbos que admiten el lema como sujeto, pues se dice Cuando se vieron solos en la oscuridad, les entró un miedo irracional; el segundo grupo de verbos toma el lema nominal como objeto directo o indirecto, como en Tus amenazas no me dan ningún miedo; y por último, el grupo de verbos que toman el lema como complemento de régimen, como en Me estremecí de miedo al oír el grito.

En el caso de vergüenza, aparece en primer lugar el verbo - en este caso solo es uno- que admite el lema como sujeto, entrar (a alguien), pues efectivamente se dicen expresiones como: «El otro día me entró vergüenza ajena en el partido MálagaRecreativo» ${ }^{8}$. En segundo lugar aparecen los verbos que toman el lema nominal como objeto directo o indirecto, en este caso dar, experimentar, sentir, pasar, tener y perder, como en: «Pasó mucha vergüenza cuando le llamaron la atención» (DCP: 1277). Por último, aparecen las combinaciones en las que vergüenza es término de una preposición, a menudo como complemento de régimen: cubrirse (de), llenarse (de), cargar (con), pues efectivamente se dice «La ciudad que carga con la vergüenza de sus antepasados»?

En estos casos, la preposición de la que es término el lema aparece explícita y entre paréntesis. Comprobamos también que el DCP nos ofrece información sobre el régimen sintáctico de algunas de las combinaciones: combinaciones que contienen preposición y que el lema constituye su término (al final).

La información sobre qué función sintáctica ocupa el lema en la combinación no aparece de forma explícita en el DCP ni tampoco utiliza este diccionario el orden de palabras para implicar esta información, a diferencia de lo que hacen otros diccionarios combinatorios porque, de acuerdo con sus autores, la flexibilidad que permite el español impediría aplicar este método con rigor. La fórmula que utiliza este diccionario para dar esta información sobre el esquema sintáctico es, además del ya mencionado orden de aparición en la entrada, es el «bloqueo o saturación de funciones» (2006: LIV). Esto significa que, por ejemplo, en la entrada abogado, aparece defender (a alguien) donde a alguien evita la confusión de interpretar la combinación como defender a un abogado. La presencia de a alguien, en palabras de los autores, bloquea o satura la función de complemento indirecto, dejando libre la de sujeto. Esto permite al lector interpretar el lema como sujeto y no como objeto.

Pero volvamos a la información sobre el régimen preposicional del lema en el DCP. Como decíamos, las preposiciones que acompañan al lema aparecen en algunas oca-

\footnotetext{
${ }^{8}$ http://foros.diariosur.es/verguenza-que-escucha-rosaleda-t41479.html

${ }^{9} \mathrm{http}: / / \mathrm{www}$.viajeros.com/diarios/berlin/berlin-14
} 
siones, es decir, cuando este es el término de la preposición (dejarse llevar por el miedo). Sin embargo, esta información no aparece de forma explícita cuando el lema rige una preposición determinada, de tal manera que, como sucede en la entrada aversión, solo podemos deducir de los ejemplos que son las preposiciones $a$, por y hacia las que introducen el objeto de este sentimiento:

aversión s.f.

CON ADJS. gran(de) · verdadera · auténtica · profunda Sentía una profunda aversión a todo tipo de escándalo $\cdot$ honda $\cdot$ tremenda $\cdot$ desmedida $\cdot$ radical $\cdot$ visceral · viva $\cdot$ congénita $\cdot$ contumaz $\cdot$ incontrolable una incontrolable aversión por los periódicos sensacionalistas · irreprimible $\cdot$ incontenible || conocida $\cdot$ clara soterrada || extraña · peculiar · característica || tradicional · histórica || personal

CON VBOS. provocar (a alguien) $\cdot$ causar (a alguien) $\cdot$ inspirar (a alguien) producir (a alguien) $\cdot$ suscitar (en alguien) $\cdot$ despertar (en alguien) $\cdot$ infundir (en alguien) $\cdot$ engendrar (en alguien) $\cdot$ alimentar || captar $\cdot$ granjearse || tener - sentir || mostrar · manifestar · confesar Terminó por confesar su radical aversión hacia todo lo que...

Si observamos la entrada apego, comprobaremos que muestra la misma situación. Al leer los ejemplos, podemos deducir que son las preposiciones por y hacia las que introducen el objeto del apego:

apego

1 apego s.m.

CON ADJS. profundo Siente un profundo apego por él · creciente · fuerte · irresistible · incondicional · estricto \| excesivo No es bueno el excesivo apego que muestra hacia... $\cdot$ desmedido || notorio $\cdot$ evidente $\cdot$ claro $\cdot$ visible $\cdot$ manifiesto $\|$ escaso $\cdot$ nulo $\cdot$ suficiente

CON SUSTS. grado (de) $\|$ falta (de) $\|$ muestra (de)

CON VBOS. tener (a algo/a alguien) Le tengo mucho apego a esta casa $\cdot$ sentir || conservar - mantener || mostrar · declarar - demostrar Lo que hizo demuestra el profundo apego que siente por $t i$

En este diccionario, como se indica en la «Guía de uso», no se menciona la presencia o ausencia de artículo u otros determinantes en las entradas del diccionario, en parte porque «la alternancia está en función de factores gramaticales que deben explicarse en los análisis sintácticos» (2006: LVII). Esta información se extrae de los ejemplos.

Así, en el ya mencionado caso de satisfacción, se extrae de los ejemplos que cuando se combina con los verbos dar, procurar, deparar, proporcionar o producir, el nombre aparece precedido de artículo o algún otro determinante. Y lo mismo ocurre con ilusión, nombre que, según Sanromán (2009), por su aspecto léxico cuando se combina con tener o similares suele ir precedido de un artículo o determinante intensivo. Una vez más, esta información también se deduce de los ejemplos:

ilusión s.f.

CON ADJS. gran(de) $\cdot$ verdadera $\cdot$ especial $\cdot$ enorme $\|$ viva $\cdot$ intensa $\cdot$ desbordante - entusiasta || falsa No se deje llevar por falsas ilusiones $\cdot$ engañosa falaz $\cdot$ infundada $\cdot$ vana $\|$ fugaz $\cdot$ efímera $\cdot$ mera $\cdot$ vaga Tenía la vaga ilusión de ganar || lejana $\cdot$ remota $\cdot$ inalcanzable || nueva $\cdot$ distinta || infantil $\cdot$ juvenil joven || óptica · pictórica || lleno, na (de) En un momento en el que se encontraba lleno de ilusiones.... • pletórico, ca (de) \|| vacío, a (de) · carente (de) · necesitado, a (de) 
CON SUSTS. inyección (de) Necesita una nueva inyección de ilusión

CON VBOS. brotar · surgir · nacer · aparecer $\|$ hacer(se) realidad Se hicieron realidad todas nuestras ilusiones $\cdot$ cumplir(se) $\cdot$ colmar(se) || desmoronar(se) $\cdot$ derrumbar(se) $\cdot$ venirse abajo $\cdot$ deshincharse $\cdot$ desinflarse $\cdot$ desvanecerse La ilusión se le desvaneció muy pronto $\cdot \operatorname{ir}(\mathbf{s e} \cdot$ extinguir(se) $\cdot \operatorname{disipar(se)} \cdot$ disolver(se) $\cdot$ difuminar(se) $\cdot \operatorname{derretir(se)} \cdot \operatorname{enfriar}(\mathrm{se}) \cdot \operatorname{aguar}(\mathrm{se}) \cdot \operatorname{ajar}(\mathrm{se}) \cdot$ desbordar(se) - decaer - decrecer || albergar Albergaba la ilusión de tener muchos hijos · abrigar · acariciar · alimentar · perseguir $\|$ hacerse Me hago la ilusión de que estoy alli $\|$ tener (por algo) · sentir · hacer (a alguien) Me hace mucha ilusión · poner (en algo) - depositar · rebosar · derrochar $\|$ conservar Conserva la misma ilusión por el trabajo que cuando era joven · mantener · perder $\|$ conceder · otorgar $\cdot$ aunar $\|$ renovar volver al trabajo con ilusión renovada crear · forjar · tejer $\cdot$ reavivar $\|$ contagiar $\cdot$ trasmitir $\cdot$ despertar $\cdot$ incentivar || echar por tierra Fue sincera conmigo, pero echó por tierra todas mis ilusiones. pulverizar · socavar || dejarse llevar (por) · aferrarse (a) · vivir (de) No podemos vivir solo de ilusiones || llenar (de) Me llena de ilusión compartir este momento contigo \|| acabar (con) $\|$ carecer (de)

En cuanto a la posibilidad de pluralizar el nombre en algunas combinaciones y la repercusión que esto tiene en el significado, el DCP divide los lemas en sublemas. Las diferencias en la flexión de número pueden venir acompañadas de una diferencia de sentido. Así ocurre en el caso de celos, que muestra una combinatoria diferente cuando se trata de celo o celos. En el caso de ganas, no aparece en singular, pero aparece una nota de uso que nos indica que se usa también en singular, y es de los ejemplos de donde deducimos en qué combinaciones resulta más natural la utilización del nombre en singular.

En cuanto a la información semántica, en el DCP se asume que las posibilidades y propiedades combinatorias de muchas palabras están en función de sus acepciones. Por ejemplo, la palabra carnicería no presenta las mismas propiedades combinatorias cuando significa comercio que cuando significa matanza. Comercio y matanza son lo que los autores del diccionario llaman pistas de sentido, que indican entre corchetes antes de presentar la combinatoria del lema para esa acepción concreta. Pero estas pistas de sentido, más amplias que una definición, solo se proporcionan en los casos en los que hay más de una acepción o «cuando se trata de acepciones poco comunes o difíciles de imaginar para un hablante no nativo». Es el caso de tajada, en el que se añade 'ventaja o provecho' (sacar tajada). En el DCP no se distinguen como acepciones diferentes los usos físicos de los figurados, porque generalmente en estos las combinatorias son idénticas o casi idénticas. Así ocurre con goteo, en cuya entrada no se distingue el uso físico de 'la acción de caer gotas' del figurado 'manifestación intermitente de algo' porque presentan la misma combinatoria.

El DCP no hace explícita en sus entradas la información semántica acerca del significado que aportan las unidades léxicas con las que se combina el lema, pero presenta los subgrupos combinatorios que están agrupados de acuerdo con criterios semánticos. En la introducción del diccionario se nos da la única pista sobre estos criterios, indicándose que se ofrece una transición gradual de los usos físicos (depositar un voto, dinero, etc.) a los figurados (depositar esperanza, ilusión, etc.). Así se ve reflejado en la entrada de depositar: 


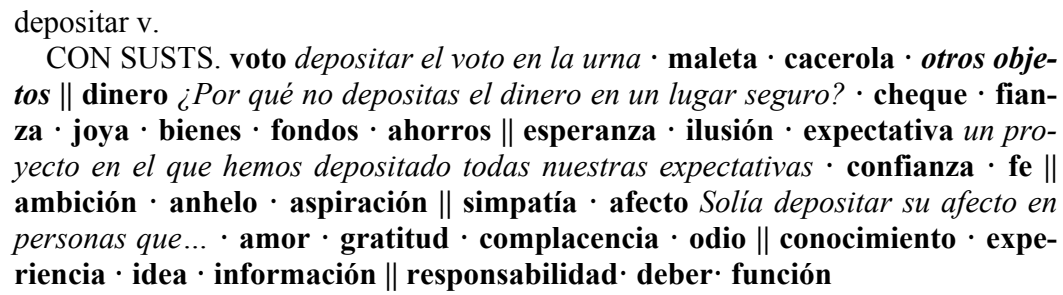

Si el usuario busca la palabra ganas en el DCP, puede observar que se combina con los adjetivos enormes, tremendas, intensas, incontenibles, irrefrenables, irresistibles y también con escasas y pocas. El establecimiento de los dos subgrupos combinatorios se marca tipográficamente con una doble barra, aunque la información de que el primer grupo intensifica y el segundo atenúa la debe poner el propio usuario. Esta división en grupos no obedece siempre a los mismos criterios. Si buscamos hormona, por ejemplo, aumentar y disminuir aparecen agrupados en lo que sería una clase semántica de 'variación de cantidad' (que no aparece explicitada) frente a otra clase integrada por segregar e inyectar.

Así pues, el DCP es un diccionario que pide del usuario conocimientos previos y la capacidad de saber rellenar huecos informativos.

\subsection{La información sintáctica y semántica en el DiCE}

Si bien el DiCE no está aun terminado, es el diccionario en español que trata las colocaciones de forma más exhaustiva desde el punto de vista sintáctico y semántico.

Al comienzo del artículo aparece la información sobre la estructura actancial, en el caso de apego, apego del individuo $X$ al $Y$. Esta información sobre los actantes nos resultará útil a la hora de interpretar el esquema de régimen:

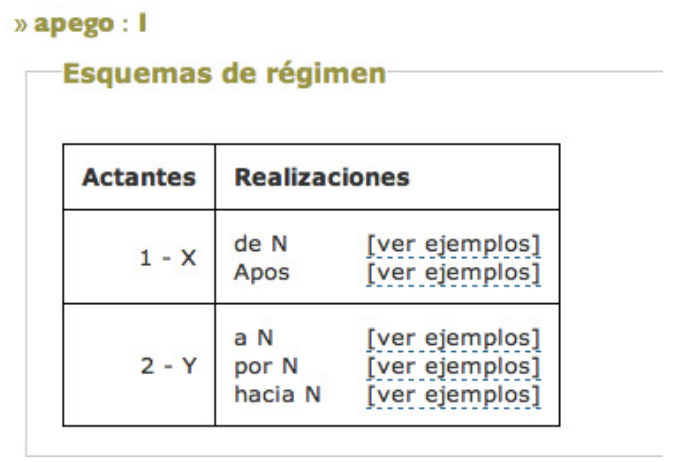

Este esquema, que utiliza una nomenclatura quizá algo críptica para el usuario no familiarizado, resulta más claro cuando pasamos el cursor por ver ejemplos y vemos las realizaciones del esquema. 


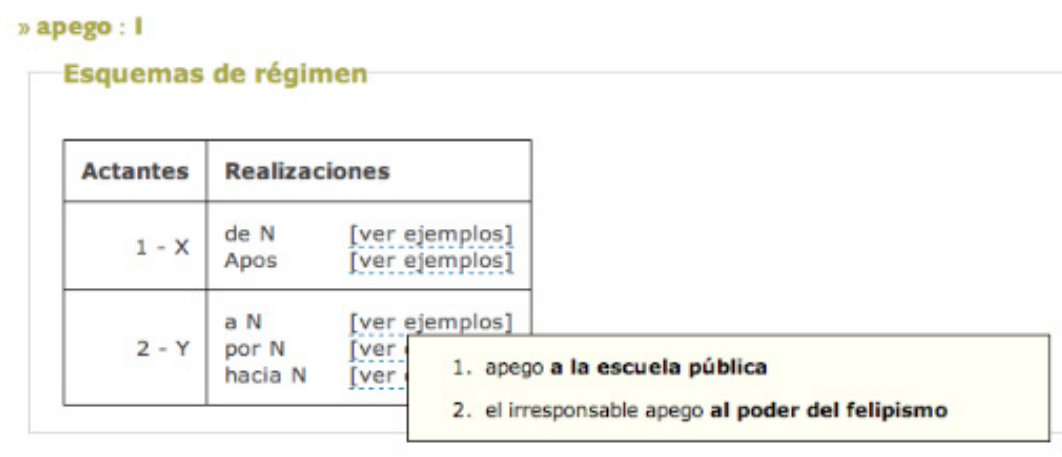

El DiCE incluye un esquema de régimen para todos los lemas, en el que utiliza una nomenclatura para describir semántica y sintácticamente las colocaciones, por medio de las glosas y las funciones léxicas. Es, pues, dentro de este marco donde encontramos las colocaciones, que están clasificadas por la categoría gramatical del colocativo, al igual que ocurría en DCP: apego + adjetivo; verbo + apego; apego + verbo; y nombre de apego. Sin embargo, no se especifica cuál es la función de apego respecto de, por ejemplo, el verbo. Si elegimos la opción verbo + apego, encontraremos todos los verbos colocativos con los que apego funciona como complemento directo o complemento de régimen, mientras que en apego + verbo estarán aquellos verbos colocativos cuyo sujeto es apego. Esta forma de disponer la información tiene la desventaja de que en español la posposición nominal respecto del verbo no necesariamente implica que el nombre funcione de objeto: en «me entraron ganas de salir», la base nominal de la colocación entrar ganas funciona como sujeto del verbo entrar y aparece en posición postverbal ${ }^{10}$.

Las restricciones acerca de los determinantes se indican a través de categorías como ART (para determinante). De este modo, y tomando el ejemplo de satisfacción analizado en los otros diccionarios, comprobaremos que la indicación acerca de la utilización del artículo en su combinación con tener aparece recogida:

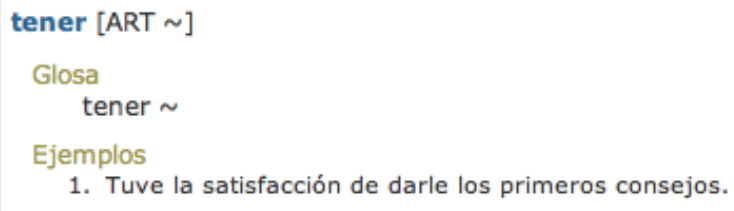

Si bien esto parece ser una tendencia (cuando tener coocurre con nombres de causa externa, el nombre suele ir acompañado de un determinante o modificador de carácter

\footnotetext{
${ }^{10}$ Alonso Ramos justifica esta decisión (2008: 4). Aunque es cierto que para el español el orden de palabras no es indicativo de la función sintáctica, hemos tomado como convención la notación «UL+Verbo» para los casos en que el lema funciona como sujeto y «Verbo+UL» para los casos en que funciona como complemento.
} 
intensivo), hemos podido comprobar cómo en el mismo diccionario se recogen también ejemplos de lo contrario, esto es, la utilización sin artículo:

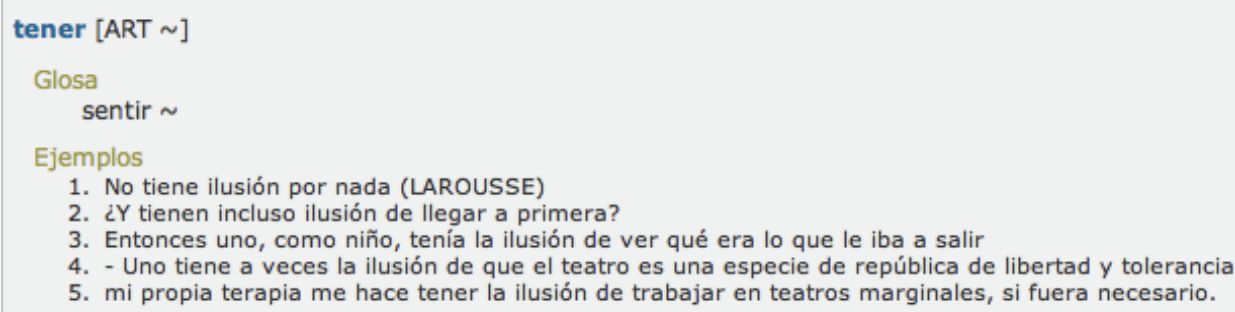

Por ello resulta difícil recoger este tipo de información en una entrada lexicográfica, donde el lector lo puede interpretar como una cuestión normativa («ilusión ha de usarse con determinante cuando se combina con tener») y podemos comprobar en la misma entrada del artículo que no siempre es así.

Respecto a la posibilidad de pluralizar el nombre, esta información se deduce de los ejemplos. En el caso de gana, no encontramos la información sintáctica en la entrada, sino que podemos observar en la mayoría de ejemplos de colocaciones que el nombre se utiliza en plural. El caso de celo es diferente, ya que se consideran dos unidades léxicas diferentes, cada una con su entrada lexicográfica.

Por último, en cuanto a la información semántica de las colocaciones, esta se da a través de las llamadas glosas, que no son más que breves indicaciones acerca del sentido de las colocaciones. Se trata de una forma de divulgar y de traducir a un lenguaje más accesible las funciones léxicas. Como reconoce la propia Alonso Ramos, «dado que las colocaciones son esencialmente un fenómeno de codificación, las glosas no deben ser formuladas como una paráfrasis que analice el sentido de la colocación, sino como un elemento que sirva para identificar el sentido que se quiere expresar» (2006: 72). Así, bajo la glosa 'causar que la $\sim$ sea menor' se agrupan diferentes verbos como aliviar, mitigar, paliar, etc., que, en combinación con nostalgia, cumplen aproximadamente el mismo papel. La autora advierte, sin embargo, que esto no quiere decir que tengan estrictamente el mismo significado.

\section{CONCLUSIONES Y LÍNEAS FUTURAS}

A la luz de este análisis - que reconocemos incompleto, pues sería necesario incluir en el análisis más diccionarios- podemos concluir que los diccionarios combinatorios y de colocaciones son, si no indispensables, sí verdaderamente útiles a la hora de obtener información sobre cómo utilizar una palabra en el discurso. Con los diccionarios generales no basta, porque estos no tratan la combinatoria léxica de forma sistemática: el número de colocaciones que ofrecen no es significativo y aquellas que aparecen no se basan en criterios de frecuencia o necesidades comunicativas más inmediatas.

Además, en los diccionarios generales no hay un posicionamiento epistemológico acerca de la direccionalidad de las colocaciones puesto que, cuando aparecen, lo hacen unas veces en la entrada de la base y en otras en la del colocativo. Tampoco es sistemá- 
tica la ubicación de las colocaciones en la entrada: pueden aparecer en la definición, en los ejemplos o en apartados específicos como el de formas complejas del DRAE, donde en se privilegia la aparición de expresiones idiomáticas.

Los diccionarios generales son instrumentos para la descodificación. A un aprendiente de ELE le pueden resultar útiles en actividades comunicativas receptivas - comprensión auditiva o de lectura-. Pueden responder a la pregunta ¿qué significa esta palabra?, pero no - o no de forma satisfactoria - a la pregunta ¿cómo utilizo esta palabra?

En el DiCE y en el DCP, teniendo en cuenta que son diccionarios especializados, el acceso a la combinatoria de una palabra está más sistematizado y la cobertura de las diferentes colocaciones es, como hemos observado, más amplia y su tratamiento lingüístico más riguroso y preciso.

Hemos podido observar que la descripción semántica es más profusa en el DiCE que en el DCP, puesto que el usuario del primero tiene que llenar el hueco de la información semántica que transmiten los subgrupos combinatorios, mientras que en el DiCE contamos con las glosas, una versión divulgativa de las funciones léxicas. En cuanto a la información sintáctica en el DCP y en el DiCE se presenta de forma diferente. En el primero a través del bloqueo o la saturación de funciones gramaticales y el orden de aparición en la entrada - una forma bastante intuitiva para el usuario no especializado- $-\mathrm{y}$ en el segundo los agrupa por funciones pero a través de convenciones basadas en el orden de palabras para los colocativos verbales.

En cuanto a la direccionalidad, como todos los diccionarios de la LEC, el DiCE es un diccionario de bases en cuyas entradas el usuario encontrará los colocativos. No obstante, se puede acceder a las bases a través de la búsqueda de los colocativos, por medio de consultas avanzadas inversas. El DCP, por su parte, es un diccionario de doble direccionalidad, donde encontramos lematizados tanto bases como colocativos.

Por último, quedaría recordar que el DCP es un diccionario en papel, lo que condiciona muchas decisiones por cuestiones de espacio. El DiCE es, por el contrario, un diccionario concebido desde el primer momento para un formato electrónico, lo que permite sin duda una mayor profusión y exhaustividad a la hora de presentar los datos. Dichas profusión y exhaustividad hacen también que la elaboración sea más lenta: de momento solo contamos con entradas de nombres de sentimiento.

Creemos, pues, que los diccionarios combinatorios son un instrumento indispensable para cubrir necesidades léxicas y gramaticales de un aprendiente de ELE. No obstante, son instrumentos que pueden resultar poco intuitivos (ya hemos visto que en el DCP el usuario debe llenar los vacíos con información tanto sintáctica como semántica). Bajo nuestro punto de vista, faltan puentes que faciliten la entrada de los diccionarios en el día a día del aula, propuestas didácticas cuyo objetivo principal sea el entrenamiento del aprendiente en su manejo ${ }^{11}$. Falta, por ejemplo, una guía estructurada para entrenar a los

\footnotetext{
${ }^{11}$ En línea con el reconocimiento de la importancia de las colocaciones en el campo de la ensenanza y aprendizaje del léxico en ELE, se están produciendo en esta última década tímidos acercamientos de los diccionarios combinatorios a la realidad y a las necesidades de los aprendientes. Así pues, contamos con algunas propuestas didácticas Higueras (2006a y 2006b), Minervini (2008) en torno al entrenamiento de estra-
} 
aprendientes y a los profesores en el uso del DCP o alusiones más frecuentes en los manuales generales de ELE. Solo llevándolos al aula se podrán detectar deficiencias o lagunas que estos puedan contener de cara al usuario no nativo y determinar así su usabilidad. Podríamos así seguir trabajando en la mejora de la práctica lexicográfica con fines didácticos en línea con la ya comentada propuesta de Ferrando (2013).

\section{REFERENCIAS BIBLIOGRÁFICAS}

Diccionarios y córpora

Alonso Ramos, Margarita (2004): Diccionario de colocaciones del español. Disponible en: http://www.dicesp.com/paginas [Consultado: 25/11/2013]

BENSON, M., E. BENSON y R. ILSON (1986): The BBI Combinatory Dictionary of English. A Guide to Word Combinations, Amsterdam-Philadelphia, John Benjamins

Bosque, Ignacio, dir. (2004): Redes. Diccionario combinatorio del español contemporáneo, Madrid, SM.

- dir. (2006): Diccionario combinatorio práctico del español contemporáneo, Madrid, SM.

Crowther, J., S. Dignen y D. LEA, eds. (2002): Oxford Collocations Dictionary for Students of English, Oxford, Oxford University Press.

DAVIES, M. (2002): Corpus del español. Disponible en línea en http://www.corpusdelespanol.org. [Consultado: 25/11/2013]

HILL, J. y M. LEwIS, eds., (1997): LTP Dictionary of Selected Collocations, Londres, LTP.

MEL'CUK, I. y A. POLGUÈRE (2007): Lexique actif du français. L'apprentissage du vocabulaire fondé sur 20000 dérivations sémantiques et collocations du français, Louvain-laNeuve, De Boeck.

MEL'ČU, I. et al. (1984-1997): Dictionnaire explicatif et combinatoire du français contemporain. Recherches lexico-sémantiques I-IV, Montréal, Les Presses de l'Université de Montréal.

Maldonado GonzÁlez, Concepción, dir. (2002 [1997]): Clave. Diccionario de uso del español actual, Madrid, SM.

ReAl aCADEMIA eSPañola (2001): Diccionario de la lengua española, Madrid, EspasaCalpe.

CREA: Corpus de referencia del español actual. Disponible en: http://corpus.rae.es/creanet.html [Consultado: 25/11/2013]

tegias para el uso de los diccionarios coordinados por Bosque (2004 y 2006), dirigidas a usuarios de nivel intermedio. Asimismo, es reseñable la plataforma en forma de quiz que se está desarrollando con el fin de dar a «conocer el Diccionario de Colocaciones del Español (DiCE)» y familiarizar al usuario con el concepto de las colocaciones, y con el contenido, la estructura y las consultas que ofrece este diccionario y que está accesible en el sitio web del diccionario. 
Rundell, M. (2010): Macmillan Collocations Dictionary: From Start to Finish, London, Macmillan Publishers Limited.

TIBERII, P. (2012): Dizionario delle collocazioni. Le combinazioni delle parole in italiano, Bolonia, Zanichelli.

\section{OBRAS DE REFERENCIA}

Alonso Ramos, M. (2002): «Colocaciones y contornos de la definición lexicográfica», Lingüistica Española Actual, XXIV, 1, pp. 63-96.

(2008): «Papel de los diccionarios de colocaciones en la enseñanza de español como L2», en E. Bernal y J. DeCesaris, eds., Proceedings of the XIII EURALEX International Congress, Barcelona, IULA, Documenta universitaria, pp. 1215-1230.

(2010): «No importa si la llamas colocación o no. Descríbela», en C. Mellado et al., eds., Nuevas propuestas para el español y el alemán, Berlin, Frank \& Timme, pp. 55-80. Disponible en línea en http://www.dicesp.com/app/webroot/files/file/Alonso $\% 2$ 02010(1).pdf [Consultado: 25/11/2013]

- y B. SANROMÁn ViLAS (2000): «Construcción de una base de datos de colocaciones léxicas», Revista de la Sociedad Española de Procesamiento del Lenguaje Natural, 24,97-98.

BALLY, C. (1909): Traité de stylistique française, París, Klincksieck.

BARRIOS RODRÍGUEZ, M. A. (2007): «Diccionarios combinatorios del español: diferencias y semejanzas entre Redes y Práctico», RedELE: Revista electrónica de didáctica lespañol lengua extranjera, 11. Disponible en línea en http://www.mecd.gob.es/dctm/redele/MaterialRedEle/Revista/2007_11/2007_redELE_1 1_01Barrios.pdf?documentId=0901e72b80df2cb7 [Consultado: $25 / 11 / 2013$ ]

BosQue, I. (2001): «Sobre el concepto de colocación y sus límites», Lingüistica Española Actual, XXIII, I, pp. 9-40.

FERRANDO, V. (2012) Aspectos teóricos y metodológicos para la compilación de un Diccionario combinatorio destinado a estudiantes de E/LE, Tarragona, Universitat Rovira i Virgili. Disponible en línea en http:/www.google.com/url?sa=t\&rct=j\&q=\&esrc=s\& source $=$ web \&cd $=1 \&$ cad $=$ rja\&uact $=8 \&$ ved $=0 \mathrm{CCoQFjAA \& url}=\mathrm{http} \% 3 \mathrm{~A} \% 2 \mathrm{~F} \% 2 \mathrm{Fwww}$. tdx.cat $\% 2$ Fbitstream $\% 2$ Fhandle $\% 2$ F $10803 \% 2 \mathrm{~F} 84025 \% 2 \mathrm{FTesis} \% 2520$ doctoral $\% 2520$ Ver\%25C3\%25B3nica\%2520Ferrando\%25202012.pdf\%3Fsequence\%3D1\&ei=-0IsU XOMpSs0AHm8IGgBA\&usg=AFQjCNG0bviztw6tHUhJ3brg9wNTM6i4VQ\&sig2=q PKEcHooBhi9JLbRw0bV6Q\&bvm=bv.62922401,d.dmQ [Consultado: 21/03/2014]

GRAGNER, S. (1998), «Prefabricated patterns in advanced EFL writing: Collocations and formulae», en A.P. Cowie, ed., Phraseology. Theory, Analysis, and Applications, Oxford, Clarendon Press, pp.145-160.

HAUSMANN, F. J. (1979): «Un dictionnaire des collocations est-il possible?», Travaux de linguistique et de littérature, 17, 1, pp. 187-195.

HigueRAS, M., (2005): «Necesidad de un diccionario de colocaciones para aprendientes de ELE», en M. ${ }^{a}$ A. Castillo et al., eds., Las gramáticas y los diccionarios en la enseñanza del español como segunda lengua: deseo y realidad. Actas del XV Congreso Internacional de ASELE, Sevilla, Universidad de Sevilla, pp. 480-490.

(2006a): «El diccionario Práctico en la práctica docente del español como lengua extranjera», en Actas del II Congreso Internacional de Lexicografia Hispánica, Alicante, Biblioteca Virtual Miguel de Cervantes. 
(2006b): Las colocaciones y su enseñanza en la clase de ELE, Madrid, Arco/Libros.

HowARTH, P. (1998): «The phraseology of learners' academic writing», en A.P. Cowie, ed., Phraseology. Theory, Analysis, and Applications, Oxford, Clarendon Press, pp. 161-186.

MEL'ČUK, I. (1998): «Collocations and Lexical Functions», en A.P. Cowie, ed., Phraseology. Theory, Analysis, and Applications, Oxford, Clarendon Press, pp. 23-53.

(1982): «Lexical Functions in Lexicographic Description», en Proceedings of the Eighth Annual Meeting of the Berkeley Linguistics Society, Berkeley, Berkeley Linguistics Society, pp. 427-424.

MINERVINI, R. (2008): «El diccionario combinatorio para el desarrollo del léxico en el aula de E/LE», en A. Nomdedeu Rull y E. Sánchez García, eds., Perspectivas de la lexicografía del español en el siglo XXI, Nápoles, L'Orientale, Dipartimento di Studi Letterari e Linguistici dell'Europa, pp. 89-119.

NATION, P. (2001): Learning vocabulary in another language, Cambridge, Cambridge University Press.

Nesselhauf, Nadja (2005): Collocations in a learner corpus, Amsterdam-Filadelfia, John Benjamins.

RUIZ, A. (2007): «La noción de colocación en las partes introductorias de algunos diccionarios monolingües del español», Revista de Lexicografia, XIII, pp. 139-182.

- (2005): «El uso del diccionario en la enseñanza y aprendizaje de las colocaciones en español», en $\mathrm{M}^{\mathrm{a}}$ A. Castillo et al., eds., Las gramáticas y los diccionarios en la enseñanza del español como segunda lengua: deseo y realidad, Actas del XV Congreso Internacional de ASELE, Sevilla, Universidad de Sevilla, pp.785-790.

TUTIN, A. (2005): «Le dictionnaire de collocations est-il indispensable?», Revue Française de Linguistique Appliquée, X, 2, pp. 31-48.

Tutin, A. y F. GROSSMANN (2002): «Collocations régulières et irrégulières: esquisse de typologie du phénomène collocatif», Revue Française de Linguistique Apliquée, 7, pp. $7-26$. 